\title{
DAMAGE CHARACTERISTICS OF SANDSTONE SUBJECTED TO PRE-PEAK AND POST- PEAK CYCLIC LOADING
}

\author{
Yubao ZHANG ${ }^{1,2,3)}$, Tongbin ZHAO ${ }^{1,2)}{ }^{*}$, Abbas TAHERI ${ }^{3)}$, Yunliang TAN ${ }^{1,2)}$ and Kai FANG ${ }^{1,2)}$ \\ 1) State Key Laboratory of Mining Disaster Prevention and Control Co-founded by Shandong Province and the Ministry of Science and \\ Technology, Shandong University of Science and Technology, Qingdao, Shandong 266590, China \\ 2) College of Mining and Safety Engineering, Shandong University of Science and Technology, Qingdao Shandong 266590, China \\ 3) School of Civil, Environmental and Mining Engineering, The University of Adelaide, Adelaide, SA 5005, Australia
}

*Corresponding author's e-mail: ztbwh2001@163.com

\begin{tabular}{l} 
ARTICLE INFO \\
\hline Article history: \\
Received 8 November 2018 \\
Accepted 19 February 2019 \\
Available online 28 February 2019 \\
\hline
\end{tabular}

\section{Keywords:}

Rock damage

Energy dissipation

Cyclic loading

Post-peak behaviour

Confining pressure

\begin{abstract}
The stability of underground openings concerns the safety of field personnel and engineering facilities in tunnelling and underground mining. The pre- and post-peak damage characteristics of sandstone subjected to triaxial cyclic loading were experimentally studied. The results show that the maximum dissipated energy occurs after the peak stress. The maximum of energy dissipation ratio $K$ and the stress ratio at the $K$ peak point increased with the confining pressure. To estimate the damage characteristics of rock material, the damage variable $D$ was defined based on rock dissipated energy. It is found that the confining pressure has a negligible influence on the damage variable $D$ rate in the pre-peak stage. However, it increased at a lower rate with the increase of confining pressure in the post-peak stage. It is found that the proposed rock damage variable associated with dissipated energy and confining pressure, is a significant indicator of the overall loss of load-carrying capacity of rock in pre-peak and post-peak stages.
\end{abstract}

\section{NOMENCLATURE}

$U$ total strain energy

$U^{e} \quad$ elastic strain energy

$U^{d} \quad$ dissipated energy

$q \quad$ deviatoric stress

$q_{f} \quad$ peak deviatoric stress

$q / q_{f}$ stress ratio

$K \quad$ energy dissipation ratio

$D$ damage variable

$m$ number of cyclic loading before a point A

$n$ total number of cyclic loading in test

\section{INTRODUCTION}

In tunneling and underground mining, the stability of underground openings is constantly under threat by various geological hazards such as rock burst, roof fall, water inrush, and spalling failures (Weng et al., 2017; Ma et al., 2017; Huang et al., 2018; Zhao et al., 2018). In underground excavations, surrounding rock frequently undergoes cyclic loading and unloading as a result of blasting, mechanical excavation and traffic system, which may result in a damage and failure. When the rock is subjected to cyclic loading, the crack initiation, propagation and coalescence may induce the degradation in mechanical properties and instability issues. Therefore, the understanding of damage evolution of rocks under cyclic loading is important for ground control.
Many experimental works have been conducted to study the strength, deformability, and failure characteristics of rocks under cyclic loading conditions, such as uniaxial cyclic loading test (Rao and Ramana, 1992; Akesson et al., 2004; Bagde and Petros, 2005; Song et al., 2013; Meng et al., 2016), triaxial cyclic loading test (Gatelier et al., 2002; Ma et al., 2013; Wang et al., 2013; Yang et al., 2015; Taheri et al., 2016), and Brazilian disc test (Erarslan and Williams 2012). Furthermore, the irreversible axial strain, the material stiffness degradation, and the energy dissipation have been used to quantitatively investigate the damage characteristics of rocks to evaluate the stability of underground excavations (Zhou et al., 2015; Liu et al., 2016; Munoz and Taheri, 2017). The constitutive model of rock material is the foundation for design and assessment in rock engineering. Many attempts have been made to propose constitutive models to simulate for rock damage behaviour (Wang et al., 2007; Zhou and Zhu, 2010; Ji et al., 2014; Nazarova et al., 2015). Shojaei et al. (2014) developed a continuum damage mechanics based constitutive model to describe elastic, plastic and damage behavior of porous rocks. Zhou et al. (2015) established a damage model considering the cyclic uniaxial stress and cyclic temperature for basalt rocks. Liu et al. (2016) developed a new damage constitutive model based on energy dissipation to describe the degree of compactness of rocks 

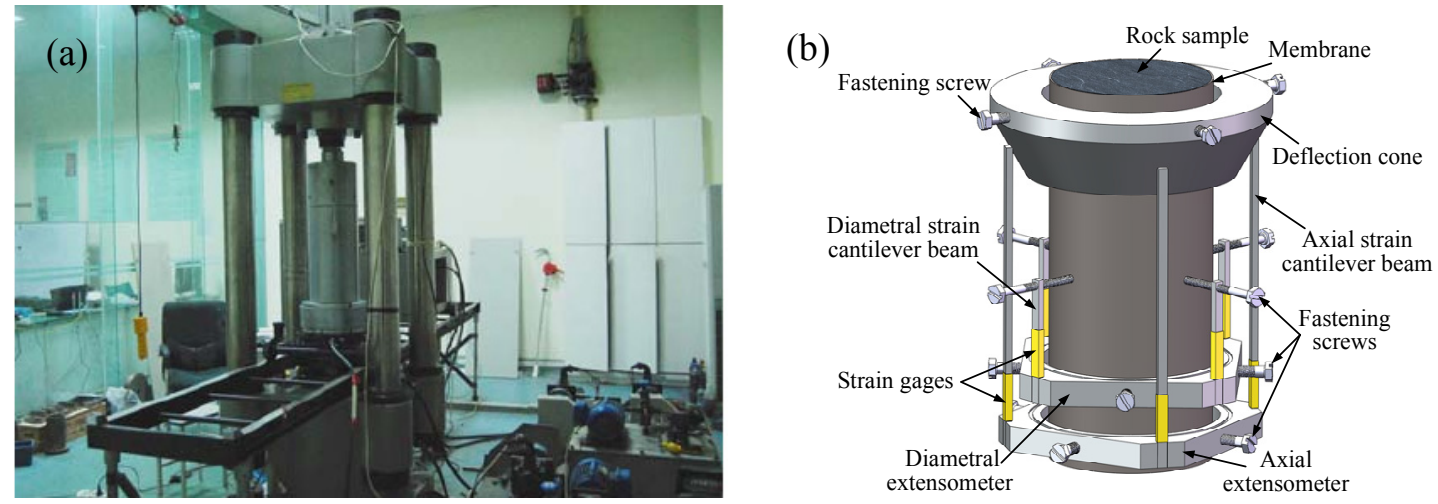

Fig. 1 Experimental set-up: (a) rock testing machine, (b) installation schematic of axial and diametral extensometers.

accurately. Nezhad et al. (2016) presented a simplified multiscale damage model for the transversely isotropic shale rocks under tensile loading. Liu et al. (2018) proposed a damage model in the form of Logistic equation to simulate the stress-strain relation of brittle rock under uniaxial compression. However, the available experimental investigations and damage models didn't reasonably describe the complete damage characteristics of rocks including both the pre-peak and post-peak stages. Also, the damage behaviour of rock under cyclic loading is mainly investigated in uniaxial loading condition, the influence of confining pressure has not been considered properly.

Due to the problems mentioned above, the present study focuses primarily on studying damage evolution characteristics of sandstone subjected to triaxial compressive cyclic loading in pre-peak and post-peak stages. To do so, firstly, a series of cyclic loading triaxial compression tests is conducted on sandstone samples under different confining pressures. Then, the energy evolution with the stress level ratio is analyzed based on the cyclic loading curves. Finally, the damage variable is defined using the energy dissipation theory, to estimate the damage characteristics of the rock in the pre-peak and the post-peak stages.

\section{MATERIALS AND METHODS}

\subsection{SAMPLE PREPARATION}

To undertake the experimental study, the sandstone specimens were cored from rock blocks that collected from immediate roof of Suncun coal mine at $-1100 \mathrm{~m}$ level, Shandong Province, China. Then the samples were trimmed and lapped to $50 \mathrm{~mm}$ in diameter and $100 \mathrm{~mm}$ in height, following the ISRM suggested methods (Ulusay and Hudson, 2007).

\subsection{TESTING SET-UP AND PROCEDURE}

The cyclic loading-unloading triaxial tests were conducted using RLJW-2000 servo-controlled rock testing machine, as shown in Figure 1(a). The direct contact extensometers, as depicted in Figure 1(b), were used to record axial and diametrical displacements. The diametrical displacement was measured at the mid-height of the specimen. In order to reduce the bedding effect associated to axial deformation of both platen-specimen contacts (Kim et al., 1994; Hakala and Heikkilä, 1997; Korinets and Alehossein, 2002), the axial extensometer was located at approximately 10 and $90 \%$ of the specimen's axial dimension using the fastening screws. As shown in Figure 1(b), the axial extensometer consists of four strain-gage cantilever beams and a deflection cone. The strain-gage cantilever beams were mounted on a rig and fastened to the lower part of rock sample. The deflection cone sat on the beams and was fastened to the upper part of rock sample. A compression of the rock sample would displace the cone and beams, resulting in a change in voltage in the strain gage circuitry which was later converted to axial strain.

The confining pressure $\sigma_{3}$ was set as $5 \mathrm{MPa}$, $10 \mathrm{MPa}, 20 \mathrm{MPa}$ and $30 \mathrm{MPa}$, respectively. At the start of the tests, the axial and confining pressures were increased simultaneously at a rate of $0.1 \mathrm{MPa} / \mathrm{s}$ until the desired confining pressure was reached. After that, the axial pressure was increased to the first deviatoric stress level at a controlled axial displacement rate of $0.02 \mathrm{~mm} / \mathrm{s}$ while keeping the confining pressure constant, and then the specimen was unloaded to zero deviatoric stress. In next cycle, the axial pressure was increased to the second deviatoric stress level, and the specimen was unloaded again. Damage-controlled cyclic loading test was carried out in this fashion until specimen failed. In the post-peak stage, the specimen was axially unloaded when sample showed signs of failure, i.e. axial load drops, until deviatoric stress was zero. Three groups of experiment were carried out under the same confining pressure. The unloading deviatoric stress levels at the pre-peak stage were set at $10 \%, 20 \%$, $30 \%, 40 \%, 50 \%, 60 \%, 70 \%, 80 \%, 90 \%$ and $100 \%$ of the peak strength.

\section{RESULTS AND DISCUSSION \\ 3.1. STRESS-STRAIN CURVES AND FAILURE CHARACTERISTIC}

The mechanical parameters of the sandstone under cyclic triaxial compression are shown in 


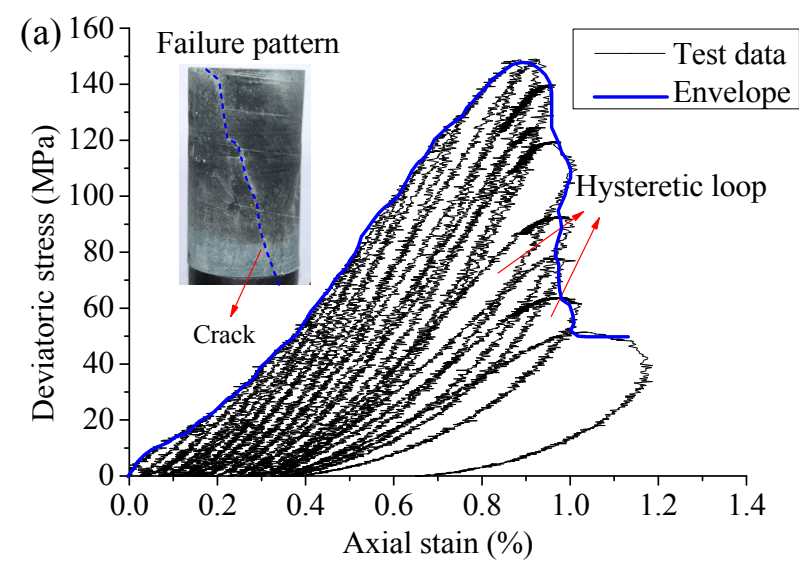

(b)

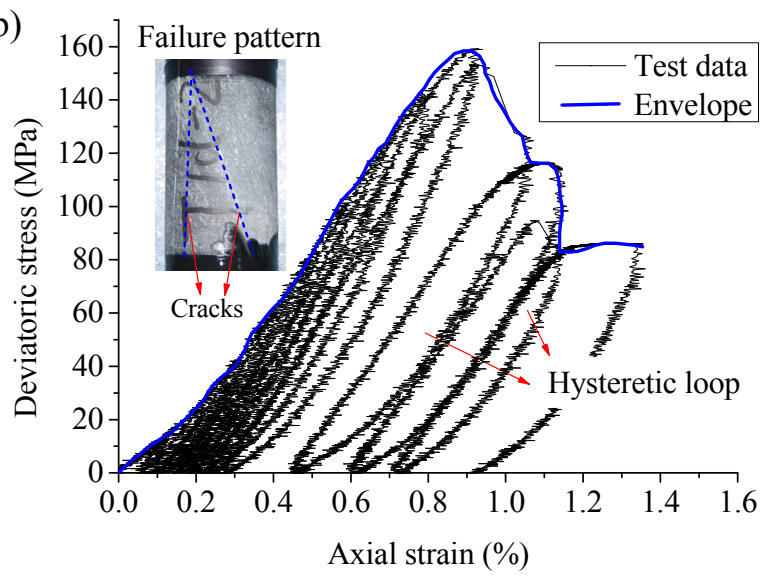

(c)

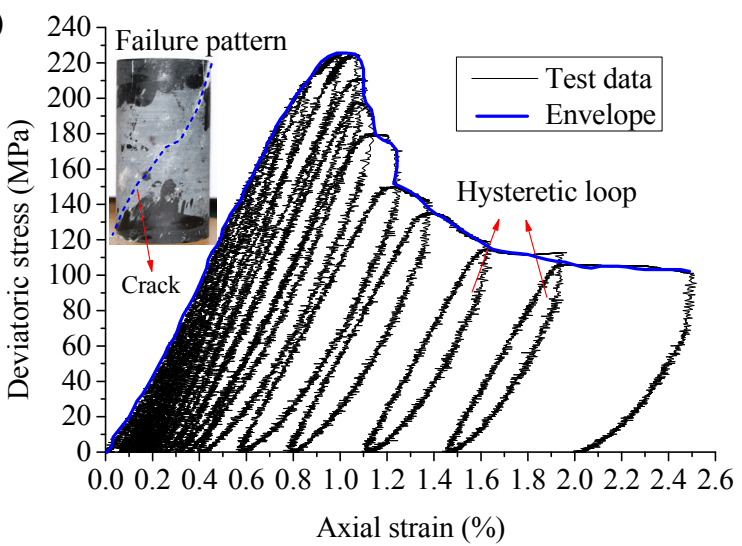

(d) $\quad 2807$ Failure pattern

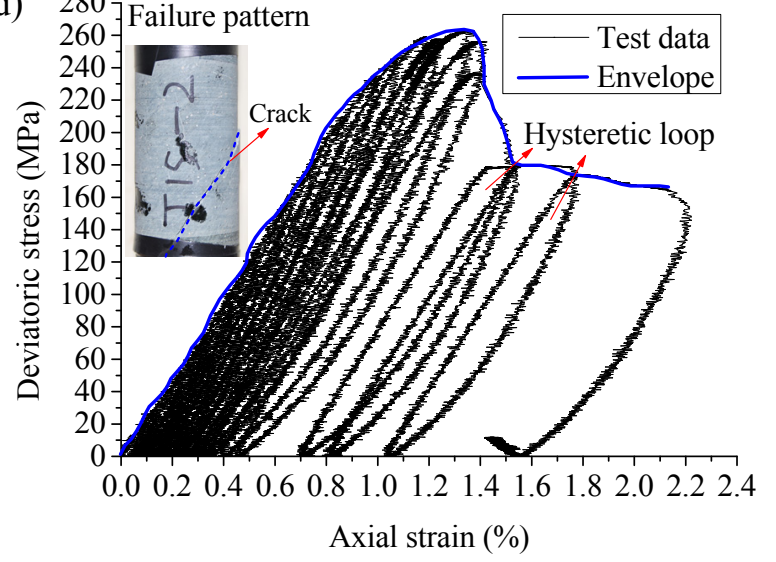

Table 1 . It can be seen that the elasticity modulus and the peak strength increased with an increase in confining pressure. Figure 2 shows the stress-strain curves and failure pattern, where the overall behaviour was highlighted by connecting the upper boundary of the original test data.

Previous studies on the complete stress-strain behaviour of rocks undergoing compression classify rocks into two categories: class I, showing negative post-peak slope response where failure is controllable, and class II, showing positive post-peak slope where failure is uncontrollable (Hudson et al., 1971; Munoz et al., 2016a). Munoz et al. (2016b) showed that most of the rocks when loaded under unconfined conditions, show either class II or combinations of class I and class II failure behaviour. As it is shown in Figure 2, for all the confining pressures, the overall post-peak response of samples is mostly a combination of class I and class II behaviour. The behaviour becomes more ductile with an increase in confining pressure. It is worth noting that as the loading method is axial displacement controlled, therefore, control of rock behaviour after the peak point is difficult, especially when confining pressure is low. As a result, measuring the post-peak response of the rock at some percentages of peak strength was not achievable (see Fig. 2). Also, after a strain softening behaviour the stress-strain curve becomes a plateau when the sample reaches to its residual strength in each test. The plateau appears earlier with an increase in confining pressure (see the residual strength column in Table 1).

The failure modes drawn in Figure 2 show that one or two main shear planes were formed when the samples were failed under different confining pressures. The area of hysteretic loop increased with the increasing stress at the pre-peak stage, and decreased at the post-peak stage, indicating that the energy dissipation leads to the degradation of the physical parameters of the rock during compression.

For the cyclic loading tests, a secant Young's modulus was calculated from the stress-strain curve for each cycle. This Young's modulus was defined as the slope of a line from the point with the lowest stress to the point with the highest stress during a cyclic loading. Figure 3 shows the evolution of Young's modulus of sandstone specimens with the increase in cycle number. Most the damage-controlled tests represent Young's modulus are decreased with the increasing number of cycle (Eberhardt et al., 1999; Heap et al., 2009). Moreover, Yang et al. $(2015,2017)$ reported that Young's modulus increases for the first few cycles and decreases afterwards, and the evolution of Young's modulus could be characterized as having four stages: A-material strengthening; Bmaterial degradation; C-shear failure; and D-structure slippage. As shown in Figure 3, the curves of Young's modulus can also be divided into four stages. It could

Fig. 2 Stress-strain curves and the failure pattern of sandstone rocks tested with different confining pressures: (a) $\sigma_{3}=5 \mathrm{MPa}$, (b) $\sigma_{3}=10 \mathrm{MPa}$, (c) $\sigma_{3}=20 \mathrm{MPa}$, and (d) $\sigma_{3}=30 \mathrm{MPa}$. 
Table 1 The mechanical parameters of sandstone.

\begin{tabular}{cccccccccccc}
\hline $\begin{array}{c}\text { Confining } \\
\text { pressure } \\
\text { /MPa }\end{array}$ & No. & \multicolumn{2}{c}{ Density $/ \mathrm{g} \cdot \mathrm{cm}^{-3}$} & \multicolumn{2}{c}{$\begin{array}{c}\text { Elasticity } \\
\text { modulus /GPa }\end{array}$} & \multicolumn{2}{c}{ Poisson's ratio } & \multicolumn{2}{c}{$\begin{array}{c}\text { Peak strength } \\
\text { /MPa }\end{array}$} & \multicolumn{2}{c}{$\begin{array}{c}\text { Residual strength } \\
\text { /MPa }\end{array}$} \\
\cline { 2 - 13 } & & value & Mean & value & Mean & value & Mean & value & Mean & value & Mean \\
\hline \multirow{2}{*}{5} & $1-1$ & 2.31 & & 21.52 & & 0.22 & & 148.54 & & 43.61 & \\
& $1-2$ & 2.24 & 2.25 & 22.81 & 20.87 & 0.21 & 0.22 & 152.81 & 148.51 & 47.39 & 45.35 \\
& $1-3$ & 2.20 & & 18.27 & & 0.23 & & 144.17 & & 45.04 & \\
\hline \multirow{2}{*}{10} & $2-1$ & 2.37 & & 21.98 & & 0.23 & & 168.93 & & 89.55 & \\
& $2-2$ & 2.20 & 2.29 & 22.68 & 21.44 & 0.24 & 0.23 & 160.11 & 164.29 & 85.24 & 83.85 \\
& $2-3$ & $2 . .31$ & & 19.66 & & 0.22 & & 163.82 & & 76.77 & \\
\hline \multirow{2}{*}{20} & $3-1$ & 2.25 & & 25.43 & & 0.21 & & 237.58 & & 115.19 & \\
& $3-2$ & 2.23 & 2.23 & 24.11 & 23.89 & 0.24 & 0.23 & 218.49 & 227.40 & 101.66 & 106.99 \\
& $3-3$ & 2.22 & & 22.14 & & 0.24 & & 226.14 & & 104.12 & \\
\hline \multirow{2}{*}{30} & $4-1$ & 2.19 & & 25.34 & & 0.22 & & 266.78 & & 170.34 & \\
& $4-2$ & 2.29 & 2.24 & 22.47 & 24.66 & 0.20 & 0.21 & 263.09 & 262.86 & 166.97 & 165.81 \\
& $4-3$ & 2.24 & & 26.16 & & 0.21 & & 258.71 & & 160.11 & \\
\hline
\end{tabular}

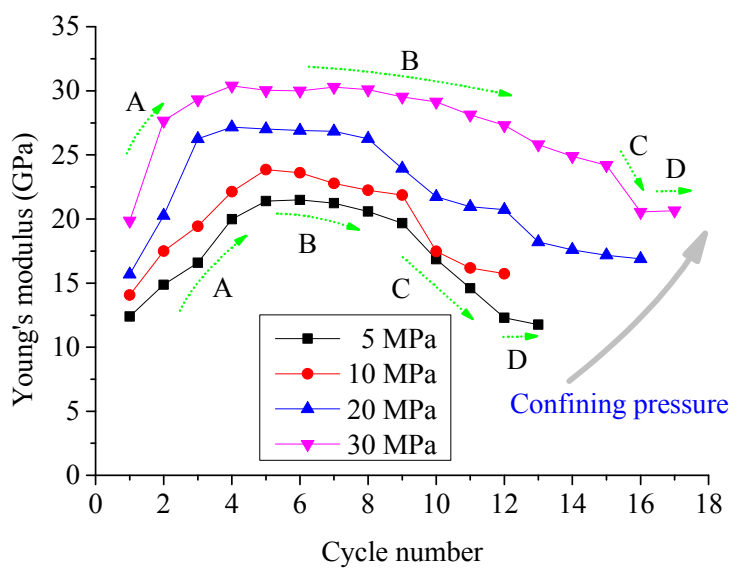

Fig. 3 Evolution of Young's modulus of sandstone with the increase in cycle number.

be observed in Figure 3 that, with the increase of confining pressure, cycle number decreases obviously in material strengthening stage $A$ and increases significantly in material degradation stage B.

In stage $\mathrm{A}$, the confining pressure accelerates the closure of pre-existing pores and fissures in the rock material resulting in a rapid increase of Young's modulus. As confining pressure increases, the material strengthening finishes at a lower stress level and needs less cyclic loading. In stage B, mechanical properties decay and result in a progressive reduction in Young's modulus. With the increase of confining pressure, cyclic loading induced damage reduces, rock reduction rate of load-bearing capacity after the peak stress becomes more gentle, therefore, post-peak stiffness increases. Consequently, the specimen needs more cyclic loading until it reaches to its residual strength. In stage C, macroscopic cracks are formed in the specimen, resulting in a quick decrease of Young's modulus. The specimen is mainly supported by friction slippage in the macroscopic fracture and reaches the residual strength during stage $\mathrm{D}$, where Young's modulus reaches to its minimum value.

\subsection{ENERGY ANALYSIS}

The dissipated energy is a critical parameter to estimate the damage mechanism of rock material.

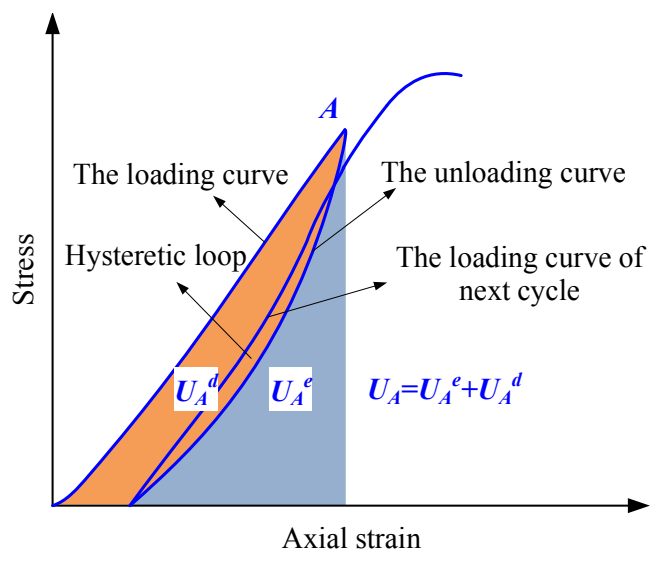

Fig. 4 Calculation model of total strain energy, elastic strain energy and dissipated energy.

Assuming that there is no thermal exchange during the deformation and damage of rock and according to first law of thermodynamics, the total energy $U$ induced by the external force to a unit volume given:

$U=U^{e}+U^{d}$

Where $U^{e}$ is the elastic strain energy and $U^{d}$ is the dissipated energy. The total strain energy $U_{A}$, elastic strain energy $U_{A}^{e}$ and the dissipated energy $U_{A}^{d}$ for a point $A$ on the strength envelope curve can be calculated based on the stress-strain curve under cyclic loading and unloading as shown in Figure 4.

Figure 5 shows the strain energy values versus stress ratio $\left(q / q_{f}\right)$ under different confining pressures. In the pre-peak stage, $U, U^{e}$ and $U^{d}$ consistently increase with an increase in the stress ratio, with the $U>U^{e}>U^{d}$. The increase of $U^{e}$ is more significant compared to $U^{d}$, indicating that the energy behaviour of the rock in the pre-peak stage mainly behaves as energy accumulation. When the stress ratio is close to 1.0 , the internal structure of rocks changed significantly, and irreversible damage gradually develops in the specimen.

In post-peak stage, $U$ and $U^{e}$ decrease with a decrease in stress ratio, however, the $U^{d}$ increases first and then decreases due to significant reduction in 
deviatoric stress. Therefore, the maximum dissipated energy does not occur at the peak stress ratio but after the peak. To further investigate the evolution of elastic and dissipated energy in pre- and post-peak stages, an energy dissipation ratio, $K$, is defined as:

$K=\frac{U^{d}}{U^{e}}$

$K=0$ represents no damage occurs, and the dissipated energy is zero. The increase of the dissipated energy means more damage accumulation. Therefore, $K$ ratio is used in this study to demonstrate accumulation of damage in sandstone rock sample during pre- and post-peak loading under different confining pressures.

Figure 6 shows $K$ decreases with an increase in stress ratio in section I. This is mainly happening due to closure of existing micro cracks and fissures in rock sample. In section II, which is mainly the area that cyclic loading is occurring, after the crack initiation stress and before the crack damage stress (Hallbauer et al., 1973), $K$ values slightly decrease or remain constant. In this area, due to crack initiation and, therefore, generation of damage, an increase in the dissipated energy is expected. This effect, however, apparently is masked by the expansion of yield surface after few loading cycles (Taheri and Tatsuoka, 2015). In section III, $K$ increases slightly, due to the generation and propagation of unstable cracks before the peak stress ratio. Unlike the pre-peak stage, in post-peak state confining pressure has significant influence on the $K$. In section VI, $K$ rapidly increases at first, and then gradually decreases with a decrease in $q / q_{f}$. As the confining pressure increases, the peak $K$ value becomes larger, and the $q / q_{f}$ at the $K$ peak point becomes larger. This is mainly because the rock behaves more ductile with an increase in confining pressure and residual strength value $\left(q / q_{f}\right.$ at the maximum $K$ ) increases. $K$ value decreases, however, when the sample approaches the residual state. In this figure, the rate of increase of $K$ values after the peak stress is higher with higher confining pressure. This is due to the lower residual strength values for the rock sample being tested without confining pressure or at the lower confining pressures. Therefore, we cannot make any conclusion on the rate of $K$ increase in postpeak stage based on the results presented in Figure 6 . The effect of confining pressure on rate of damage accumulation is discussed in the next section.

\subsection{DAMAGE CHARACTERISTICS}

A damage variable is frequently used to analyze the damage evolution and failure mechanism of rock samples. At present, a great variety of methods have been adopted to calculate the damage variable of rock material based on joint spacing, Young's modulus, yield stress, P-wave and S-wave velocity, acoustic emission event count, energy dissipation, etc. In the present study, the damage variable $D$ is defined as the
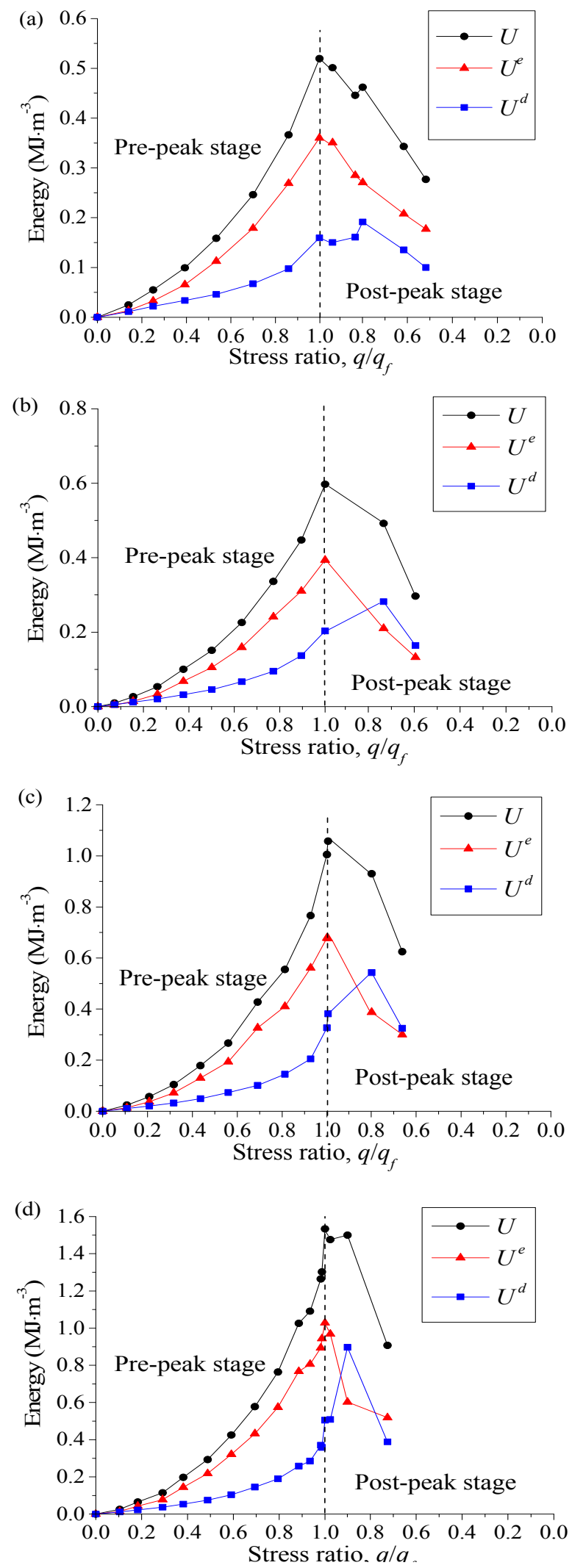

Fig. 5 Relationship curves of energy vs. stress ratio for sandstone rock with different confining pressures: (a) $\sigma_{3}=5 \mathrm{MPa}$, (b) $\sigma_{3}=10 \mathrm{MPa}$, (c) $\sigma_{3}=20 \mathrm{MPa}$, and (d) $\sigma_{3}=30 \mathrm{MPa}$. 


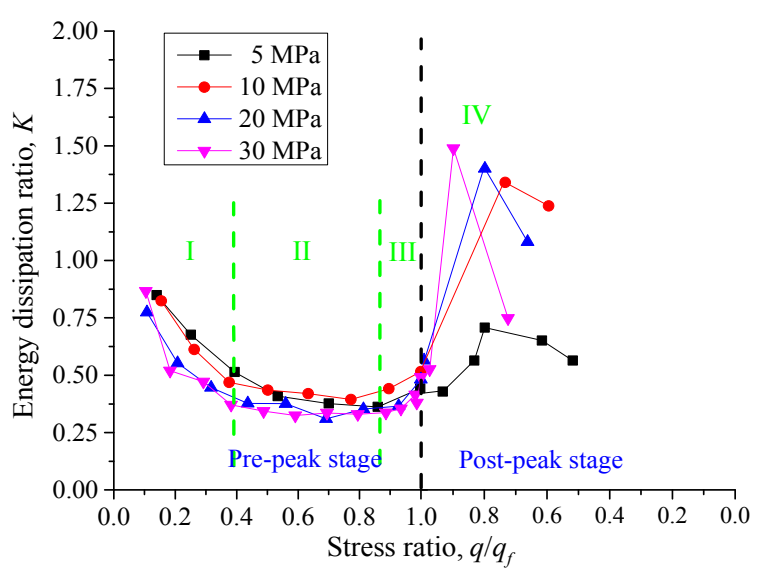

Fig. 6 Relations between energy ratio and stress ratio for different confining pressures.

ratio of the accumulative dissipated energy after $m$ cyclic loading to the total accumulative dissipated energy during the entire cyclic loading process:

$D=\frac{\sum_{I=1}^{M} U_{i}^{d}}{U_{1}^{d}+U_{2}^{d}+U_{3}^{d}+\ldots+U_{n}^{d}}$

Where $m$ is the number of cyclic loading before a point $\mathrm{A}$ and $n$ is the total number of cyclic loading. The damage variable $D$ ranges from 0 to 1 , where $D=0$ represents the rock is in a state without damage and $D=1$ represents the rock is in the residual strength stage.

Using the stress-strain relations that are obtained during cyclic loading triaxial compression test, the damage variable $D$ of sandstone specimens under different confining pressures are deduced respectively using Eq. (3). In general, the stress-strain curves follow the stages distinguished by crack initiation, crack closure, and crack damage (Taheri et al., 2016). Crack damage stress is associated with the axial strain non-linearity or to the reversal point of the total volumetric strain at the onset of dilation generated by crack development and represents the onset of unstable crack growth, which is characterized by significant structural changes to the rock (Hallbauer et al., 1973). As shown in Figure 7, the $\mathrm{S} 1$ is the initial damage stage (where the sample experiences crack closure and then crack initiation) before the crack damage stress. The S2 is the secondary damage stage when volumetric strain starts to increase after the crack damage and before the peak stress. The S3 is the post-peak strain softening stage (damage rate increases significantly), and the $\mathrm{S} 4$ is the residual strength stage. The S2 and S3 stages are the key regions to evaluate the damage behaviour of rock in pre-failure and post-failure stages.

As it may be seen in Figure 7, D gradually increases in S1 stage and then rapidly in S2 stage until the peak stress point. In the post-peak stage (i.e. S3 and S4), damage increases dramatically and in a very fast rate until the sample reaches to the residual stage. The increment of $D$ in the $\mathrm{S} 3$ stage is approximately two times the sum of $D$ increments in the previous stages. In S3, the specimens gradually experienced
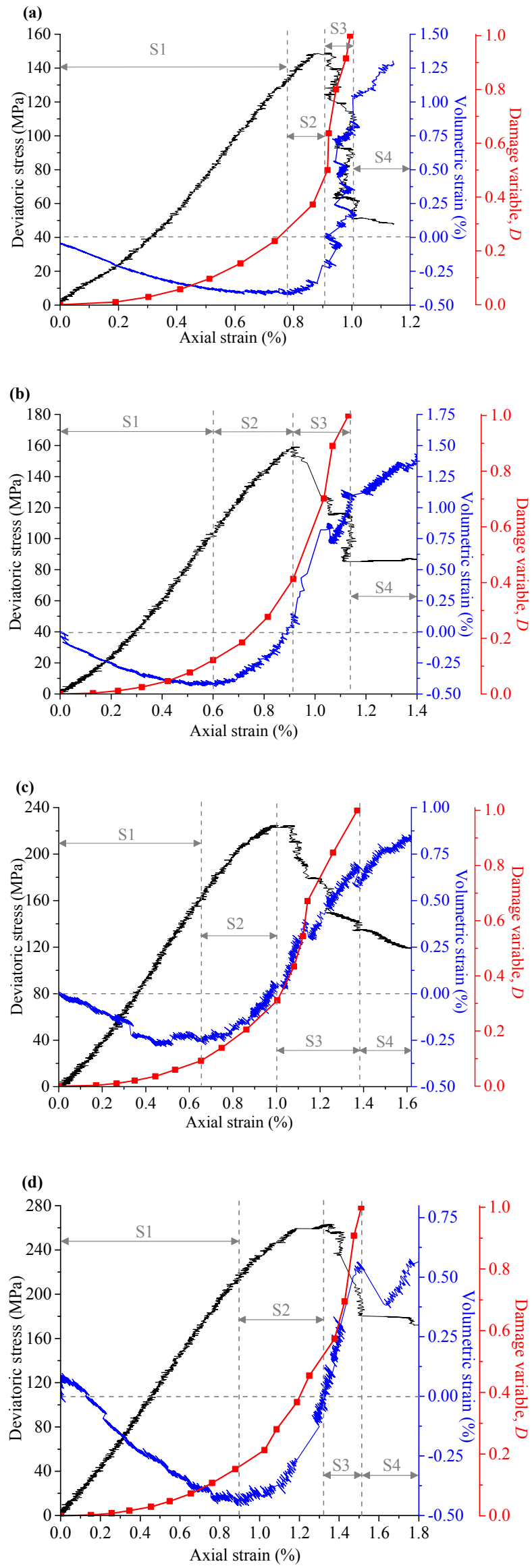

Fig. 7 Stress-strain behaviour and damage variables of sandstone under different confining pressures: (a) $\sigma_{3}=5 \mathrm{MPa}$, (b) $\sigma_{3}=10 \mathrm{MPa}$, (c) $\sigma_{3}=20 \mathrm{MPa}$, and (d) $\sigma_{3}=30 \mathrm{MPa}$. 


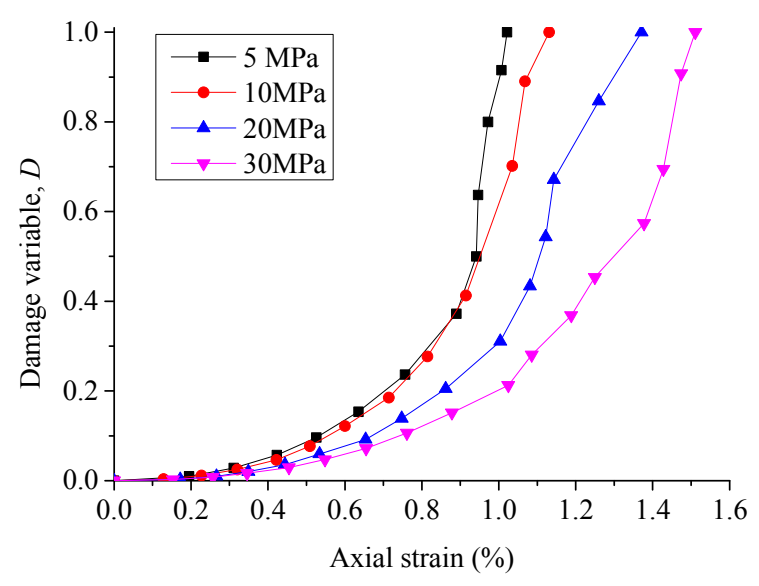

Fig. 8 Damage variable $D$ versus axial strain.

a propagation of micro cracks and a global failure when $D$ approaches 1.0 .

To investigate the effects of confining pressure on the evolution of damage during pre- and post-peak cyclic loading, the damage curves are plotted against axial strain and demonstrated in Figure 8. It may be seen in this figure with the small deformation of the pre-peak stage, the confining pressure had a little effect on the damage rate. In the post-peak stage, however, $D$ develops faster in the lower confining pressure loading test and slower in the tests with higher confining pressure. Under a high confining pressure, the sandstone behaves more ductile, therefore, shearing, in terms of axial strain, is longer. In the post-peak stage, cracks propagate to the boundaries of rock specimens, and the system of intersecting and coalescing cracks in an unstable manner form a fault or localised failure surface (Tutluoğlu et al., 2015). The increase of confining pressure moderates the development of failure surface, resulting in the increase of internal damage in rock specimen in a lower rate.

\section{CONCLUSIONS}

A series of cyclic loading triaxial compression tests were conducted on sandstone samples under different confining pressures. It is found that the overall post-peak response of samples is mostly a combination of class I and class II behaviour, which including positive and negative post-peak slopes where failure is uncontrollable, regardless of the amount of confining pressure. With the increase of confining pressure, rock reduction rate of load-bearing capacity after the peak stress becomes more gentle, therefore, post-peak stiffness increases.

Energy analysis shows that the maximum of dissipated energy is not at the peak stress ratio but after the peak. In pre-peak stage, the influence of confining pressure on energy dissipation ratio $K$ is very small. On the contrary, in the post-peak stage, the greater the confining pressure is, the larger the maximum $K$ value is. Furthermore, the damage variable $D$ was defined as the ratio of the accumulative dissipated energy after $m$ cyclic loading to the total accumulative dissipated energy to estimate the damage response of crack propagation inside the rock. Effect of confining pressure on variations of $D$ in the pre-peak stage was observed to be negligible. In the post-peak stage, however, the damage variable increased by a lower rate with the increase of confining pressure. Therefore, rock damage, in association with the dissipated energy and confining pressure, is a major contributing factor to the overall loss of load-carrying capacity of rock specimen in prepeak and post-peak stages.

\section{ACKNOWLEDGMENTS}

The authors would like to acknowledge the financial support of the National Key Research and Development Plan of China (No.2017YFC0603001), National Natural Science Foundation of China (No. 51674160, 51408345), Taishan Scholar Talent Team Support Plan for Advantaged and Unique Discipline Areas, and China Scholarship Council (No. 201708370105).

\section{REFERENCES}

Akesson, U., Hansson, J. and Stigh, J.: 2004, Characterisation of microcracks in the Bohus granite, western Sweden, caused by uniaxial cyclic loading. Eng. Geol., 72, No. (1-2), 131-142. DOI: $10.1016 /$ j.enggeo.2003.07.001

Bagde, M.N. and Petros, V.: 2005, The effect of machine behavior and mechanical properties of intact sandstone under static and dynamic uniaxial cyclic loading. Rock Mech. Rock Eng., 38, No. 1, 59-67. DOI: $10.1007 / \mathrm{s} 00603-004-0038-\mathrm{Z}$

Eberhardt, E., Stead, D. and Stimpson, B.: 1999, Quantifying progressive pre-peak brittle fracture damage in rock during uniaxial compression. Int. J. Rock Mech. Min. Sci., 36, No. 3, 361-380. DOI: 10.1016/S0148-9062(99)00019-4

Erarslan, N. and Williams, D.J.: 2012, The damage mechanism of rock fatigue and its relationship to the fracture toughness of rocks. Int. J. Rock Mech. Min. Sci., 56, 15-26. DOI: 10.1016/j.ijrmms.2012.07.015

Gatelier, N., Pellet, F. and Loret, B.: 2002, Mechanical damage of an anisotropic porous rock in cyclic triaxial tests. Int. J. Rock Mech. Min. Sci., 39, No. 3, 335354. DOI: 10.1016/S1365-1609(02)00029-1

Hakala, M. and Heikkilä, E.: 1997, Laboratory testing of Olkiluoto mica gneiss in borehole OL-KR 10. Work Report POSIVA-97-07e. Posiva Oy, Helsinki, 79.

Hallbauer, D.K., Wagner, H. and Cook, N.G.W.: 1973, Some observations concerning the microscopic and mechanical behaviour of quartzite specimens in stiff, triaxial compression tests. Int. J. Rock Mech. Mining Sci. Geo. Abs., 10, No. 6, 713-726. DOI: 10.1016/0148-9062(73)90015-6

Heap, M.J., Vinciguerra, S. and Meredith, P.G.: 2009, The evolution of elastic moduli with increasing crack damage during cyclic stressing of a basalt from Mt. Etna volcano. Tectonophysics, 471, No. 1-2, 153-160. DOI: $10.1016 /$ j.tecto.2008.10.004

Huang, W.P., Yuan, Q., Tan, Y.L., Wang, J., Liu, G.L., Qu, G.L. and Li, C.: 2018, An innovative support technology employing a concrete-filled steel tubular structure for a 1000-m-deep roadway in a high in situ stress field. Tunn. Undergr. Sp. Tech., 73, 26-36. DOI: 10.1016/j.tust.2017.11.007 
Hudson, J.A., Brown, E.T. and Fairhurst, C.: 1971, Optimizing the control of rock failure in servocontrolled laboratory tests. Rock Mechanics, 3, No. 4, 217-224. DOI: 10.1007/BF01238181

Ji, M., Zhang, Y.D., Liu, W.P. and Cheng, L.: 2014, Damage evolution law based on acoustic emission and Weibull distribution of granite under uniaxial stress. Acta Geodyn. Geomater., 11, No. 3, 269-277. DOI: 10.13168/AGG.2014.0006

Kim, Y.-S., Tatsuoka, F. and Ochi, K.: 1994, Deformation characteristics at small strains of sedimentary soft rocks by triaxial compression tests. Geotechnique, 44, No. 3, 461-478. DOI: 10.1680/geot.1994.44.3.461

Korinets, A. and Alehossein, H.: 2002, On the initial nonlinearity of compressive stress-strain curves for intact rock. Rock Mech. Rock Eng., 35, No. 4, 319-328. DOI: $10.1007 / \mathrm{s} 00603-002-0030-4$

Liu, D., He, M. and Cai, M.: 2018, A damage model for modeling the complete stress-strain relations of brittle rocks under uniaxial compression. Int. J. Damage Mech., 27, No. 7, 1000-1019. DOI: $10.1177 / 1056789517720804$

Liu, X.S., Ning, J.G., Tan, Y.L. and Gu, Q.H.: 2016, Damage constitutive model based on energy dissipation for intact rock subjected to cyclic loading. Int. J. Rock Mech. Min. Sci., 85, 27-32. DOI: 10.1016/j.ijrmms.2016.03.003

Ma, D., Rezania, M., Yu, H.S. and Bai, H.B.: 2017, Variations of hydraulic properties of granular sandstones during water inrush: Effect of small particle migration. Eng. Geol., 217, 61-70. DOI: 10.1016/j.enggeo.2016.12.006

Ma, L., Liu, X., Wang, M., Xu, H., Hua, R., Fan, R., Jiang, S., Wang, G. and Yi, Q.: 2013, Experimental investigation of the mechanical properties of rock salt under triaxial cyclic loading. Int. J. Rock Mech. Min. Sci., 62, 34-41. DOI: 10.1016/j.ijrmms.2013.04.003

Meng, Q., Zhang, M., Han, L., Pu, H. and Nie, T.: 2016, Effects of acoustic emission and energy evolution of rock specimens under the uniaxial cyclic loading and unloading compression. Rock Mech. Rock Eng., 49, 3873-3886. DOI: 10.1007/s00603-016-1077-y

Munoz, H., Taheri, A. and Chanda, E.: 2016a, Fracture energy-based brittleness index development and brittleness quantification by pre-peak strength parameters in rock uniaxial compression. Rock Mech. Rock Eng., 49, 4587-4606. DOI: $10.1007 / \mathrm{s} 00603-016-1071-4$

Munoz, H., Taheri, A. and Chanda, E.: 2016b, Pre-peak and post-peak rock strain characteristics during uniaxial compression by 3D digital image correlation. Rock Mech. Rock Eng., 49, 2541-2554. DOI: $10.1007 / \mathrm{s} 00603-016-0935-y$

Munoz, H. and Taheri, A.: 2017, Local damage and progressive localisation in porous sandstone during cyclic loading. Rock Mech. Rock Eng., 50, No. 12, 3253-3259. DOI: 10.1007/s00603-017-1298-8

Nazarov, L.A., Nazarova, L.A., Tsoi, P.A. and Tsibizov, L.V.: 2015, Modeling evolution of damage in rock specimens under loading. J. Min. Sci., 51, No. 6, 1101-1107. DOI: 10.1134/S1062739115060356

Nezhad, M.M., Zhu, H., Ju, J.W. and Chen, Q.: 2016, A simplified multiscale damage model for the transversely isotropic shale rocks under tensile loading. Int. J. Damage Mech., 25, No. 5, 705-726. DOI: $10.1177 / 1056789516639531$

Rao, M.V.M.S. and Ramana, Y.V.: 1992, A study of progressive failure of rock under cyclic loading by ultrasonic and AE monitoring techniques. Rock Mech.
Rock Eng., 25, No. 4, 237-251. DOI: $10.1007 / \mathrm{BF} 01041806$

Shojaei, A., Taleghani, A.D. and Li, G.: 2014, A continuum damage failure model for hydraulic fracturing of porous rocks. Int. J. Plasticity, 59, 199-212. DOI: 10.1016/j.ijplas.2014.03.003

Song, H., Zhang, H., Kang, Y., Huang, G., Fu, D. and Qu, C.: 2013, Damage evolution study of sandstone by cyclic uniaxial test and digital image correlation. Tectonophysics, 608, 1343-1348. DOI: $10.1016 /$ j.tecto.2013.06.007

Taheri, A. and Tatsuoka, F.: 2015, Small- and large-strain behaviour of a cement-treated soil during various loading histories and testing conditions. Acta Geotech., 10, No. 1, 131-155. DOI: $10.1007 / \mathrm{s} 11440-014-0339-7$

Taheri, A., Yfantidis, N., Olivares, C.L., Connelly, B.J. and Bastian, T.J.: 2016, Experimental study on degradation of mechanical properties of sandstone under different cyclic loadings. Geotech. Test. J., 39, No. 4, 673-687. DOI: 10.1520/GTJ20150231

Ulusay, R. and Hudson, J.A.: 2007, The complete ISRM suggested methods for rock characterization, testing and monitoring; 1974-2006. Suggested methods prepared by the Commission on Testing Methods. International Society for Rock Mechanics: ISRM Turkish National Group, Ankara, Turkey.

Tutluoğlu, L., Öge, I.F. and Karpuz, C.: 2015, Relationship between pre-failure and post-failure mechanical properties of rock material of different origin. Rock Mech. Rock Eng., 48, No. 1, 121-141. DOI: $10.1007 / \mathrm{s} 00603-014-0549-1$

Wang, Z.C., Li, S.C., Qiao, L.P. and Zhao, J.G.: 2013, Fatigue behavior of granite subjected to cyclic loading under triaxial compression condition. Rock Mech. Rock Eng., 46, No. 6, 1603-1615. DOI: $10.1007 / \mathrm{s} 00603-013-0387-6$

Wang, Z., Li, Y. and Wang, J.: 2007, A damage-softening statistical constitutive model considering rock residual strength. Comput. Geosci., 33, No. 1, 1-9. DOI:10.1016/j.cageo.2006.02.011

Weng, L., Huang, L., Taheri, A. and Li, X.: 2017, Rockburst characteristics and numerical simulation based on a strain energy density index: a case study of a roadway in Linglong gold mine, China. Tunn. Undergr. Sp. Tech., 69, 223-232. DOI: 10.1016/j.tust.2017.05.011

Yang, S.Q., Ranjith, P.G., Huang, Y.H., Yin, P.F., Jing, H.W., Gui, Y.L. and Yu, Q.L.: 2015, Experimental investigation on mechanical damage characteristics of sandstone under triaxial cyclic loading. Geophys. J. Int., 201, No. 2, 662-682. DOI: 10.1093/gji/ggv023

Yang, S.Q., Tian, W.L. and Ranjith, P.G.: 2017, Experimental investigation on deformation failure characteristics of crystalline marble under triaxial cyclic loading. Rock Mech. Rock Eng., 50, No. 11, 2871-2889. DOI: $10.1007 / \mathrm{s} 00603-017-1262-7$

Zhou, C.Y. and Zhu, F.X.: 2010, An elasto-plastic damage constitutive model with double yield surfaces for saturated soft rock. Int. J. Rock Mech. Min. Sci., 47, No. 3, 385-395. DOI: 10.1016/j.ijrmms.2010.01.002

Zhou, S.W., Xia, C.C., Hu, Y.S., Zhou, Y. and Zhang, P.Y.: 2015, Damage modeling of basaltic rock subjected to cyclic temperature and uniaxial stress. Int. J. Rock Mech. Min. Sci., 77, 163-173. DOI: 10.1016/j.ijrmms.2015.03.038

Zhao, T.B., Zhang, Y.B., Zhang, Q.Q. and Tan, Y.L.: 2018, Analysis on the creep response of bolted rock using bolted burgers model. Geomechanics and Engineering, 14, No. 2, 141-149. DOI: 10.12989/gae.2018.14.2.141 